\title{
Study of Heat Loss from Hot Tungsten Filament Bulb Using AT89C51 Based Data Acquisition System
}

\author{
Raghavendra Rao Kanchi and Naveen Kumar Uttarkar
}

\begin{abstract}
The electrical power supplied to the filament of an electric lamp gets converted into heat rising the temperature of the filament. This experiment tries to understand the contribution of conduction, convention and radiation in heat loss from the hot tungsten filament of a partially evacuated bulb.
\end{abstract}

Index Terms-Heat loss, cold temperature of the filament, Newton's law of cooling, Stefan's law of radiation, AT89C51 microcontroller, MAX197, OP 07, LCD etc.

\section{INTRODUCTION}

In this present paper the experimental explanation for heat loss of hot tungsten is carried out. Here with simple electrical setup is used to derive the relation between the energy supplied and heat loss by hot tungsten filament bulb. In fact a hot body losses its energy in the form of three modes. They are conduction, convention and radiation.

A hot tungsten filament bulb is left to cool in air; it loses heat both by conduction-convention and radiation. When air blows over hot tungsten filament bulb it lowers the temperature of surface. Lowering the surface temperature increases the temperature gradient between its interior and exterior leading to increase in conduction. At the same time the lowering of surface temperature reduces the radiation loss from the body. This clearly shows that the cooling of bodies at temperatures not far above that of surroundings is mostly due to conduction-convention process and is accounted for by Newton's law of cooling. The heat loss due to radiation in this temperature domain must be negligible. But at higher temperatures, the hot tungsten filament bulb heat loss follows the Stefan-Boltzmann law.

Here microcontroller based tungsten filament bulb heat loss measurement system is designed. In this experiment the heat loss measurement is instrumented using AT89C51, MAX 197 IC, LM35 and OP 07 op-amps. Using this system voltage, current and temperature parameters are measured.

\section{LITERATURE REVIEW}

In the present work the heat loss from hot bodies is studied using evacuated tungsten bulb and AT89C51 based data acquisition system. The work done by various workers ${ }^{1-7}$ in this direction is given in the form of literature review as given

Manuscript received March 8, 2012; revised April 27, 2012.

The authors are with the Microprocessor and Microcontroller Lab, Department of physics, Sri Krishnadevaraya University, Anantapur, India (e-mail: naveeneimc2@gmail.com, Tel.: + 91 9966645070, fax: +08554-255710). below:

\section{A. I.R.Edmond [1]}

In this paper low wattage bulb in a Wheatstone bridge setup with the associated battery power pack for dc power supply is used. From the hardware the voltage and current are measured. The parameter, cold resistance of the filament is determined from the extrapolating $\mathrm{R}$ against $\mathrm{I}$ (current) to zero. Temperature of the filament is calculated from a linear relation.

$$
\mathrm{R}_{\mathrm{t}}=\mathrm{R}_{0}\left[1+\alpha\left(\mathrm{T}_{\mathrm{t}}-\mathrm{T}_{0}\right)\right], \alpha=0.0053 \mathrm{~K}^{-1}
$$

From the graph of $\log \mathrm{P}$ vs $\log \mathrm{T}$ is used for verification of Stefan's.

\section{B. Wray E.M. [2]}

In this experiment tungsten bulb is used in a simple ammeter-voltmeter setup which includes an autotransformer. From the hardware the reading of $\mathrm{V}$ and I are measured. From the reading of $\mathrm{V}$ and $\mathrm{I}$, resistance of the filament and power dissipated are measured. $\mathrm{R}_{0}$ and $\mathrm{T}_{0}$ are determined by extrapolating filament resistance to zero power dissipation. Temperature of the filament is calculated from a linear relation.

$$
\mathrm{R}_{\mathrm{t}}=\mathrm{R}_{0}\left[1+\alpha\left(\mathrm{T}_{\mathrm{t}}-\mathrm{T}_{0}\right)\right], \alpha=0.0053 \mathrm{~K}^{-1}
$$

The graph of $\log \mathrm{P}$ vs $\log \mathrm{T}$ is used for verification of Stefan's law.

\section{B.S.N.Prasad and Rita Mascarenhas [3]}

In this experiment tungsten bulb is used in a simple ammeter-voltmeter setup which includes an autotransformer. From the hardware the readings of V and I, resistance of the filament and power dissipated are measured. $\mathrm{R}_{0}$ and $\mathrm{T}_{0}$ are determined by extrapolating filament resistance to zero power dissipation. Temperature of the filament is calculated from an R-T relation,

$$
\left(\mathrm{R}_{\mathrm{t}} / \mathrm{R}_{0}\right)=\left(\mathrm{T}_{\mathrm{t}} / \mathrm{T}_{0}\right)^{1.2}
$$

In this paper the Stefan's law is verified.

\section{Ian Cooper [4]}

In this paper voltage and current measurements were made using a car headlight assembly (12 V, 60/50 W). Resistance of the bulb and current flowing through the bulb are measured. By extrapolation of the data(R Vs I) the resistance of the tungsten at zero current can be estimated. The graph between the $\mathrm{P}_{\text {rad }}$ against $\left(\mathrm{T}^{4}-\mathrm{T}_{0}{ }^{4}\right)$ is a straight line. This is good agreement with the Stefan's law of radiation.

\section{E. Mark Wellons [5]}

In this paper simple electric circuit with dc power supply 
and bulb is used. From the readings of voltage and current and voltage, power dissipated from bulb and temperature of the filament is measured. The cold resistance of the filament is important parameter in determination temperature of the bulb. At room temperature when voltage $\mathrm{V}$ is applied to the bulb and I is the current flowing through the bulb then the ratio of voltage and current gives the cold resistance of the bulb. Temperature of the filament is calculated from following formula,

$$
\mathrm{T}=300\left(\mathrm{R}_{\mathrm{t}} / \mathrm{R}_{0}\right)^{0.82}
$$

The graph of $\log \mathrm{P}$ vs $\log \mathrm{T}$ is used for verification of Stefan's law.

\section{F. Nazlia Omar, Rozli Zulkifli and Rosilah Hassan [6]}

The apparatus used in this experiment is located in the heat transfer laboratory, department of mechanical and materials engineering. A track is used to traverse the radiation back and forth from the radiation source. Another important instrument is a controller. This contains a rheostat to control the heat input to the heat source and readout instruments attached to the radiometer. In this experiment, only the heat source will be used not the light source.

\section{G. Imtiaz Ahmad, Sidra Khalid, and Ehsan E.Khawaja[7]}

In this present work three $12 \mathrm{~V}$ operated low power (rated at $10 \mathrm{~W}, 25 \mathrm{~W}$ and $35 \mathrm{~W}$ ) commercial lamps were studied. Current-voltage measurements were performed using a variable power supply. Multimeters were used to measure the voltage across the filament and current in the series circuit. The resistance of the bulb obtained using $R=V / I$. The temperature of the filament at different voltage was measured using a Minolta-Land infrared optical pyrometer Cyclops 52. In this work the Stefan's law is verified.

There are various methods are used for verification of heat loss from tungsten bulb. The experiment using a tungsten bulb in a simple ammeter-voltmeter setup which includes an autotransformer for voltage variations $[2,3]$ is advantageous than Wheatstone bridge setup [1].But the experiment using autotransformer is dangerous while compared with the Wheatstone bridge method. The simple circuit with voltmeter and ammeter with dc power supply is preferable for the student experiment [4, 5 and 7]. While the experimental setup with radiometer [6] is costly due to equipments used in it.

\section{SAlient Features of The Present Work}

The important feature of the present work is that current through bulb, voltage applied to the bulb and temperature of surroundings measurement is automated. In the earlier works multimeters are used for current and voltage measurement. In this paper the readings are displayed on the LCD. Here OP 07 is used in the non inverting voltage amplifier configuration. Due to its high input impedance it not acts as a load. The resolution of the MAX197 is $2.44 \mathrm{mV}$. The input voltage to the bulb and current through the bulb are signal conditioned using OP 07 circuit in order to measure using MAX197 and AT89C51. The main feature of the experimental setup is that it is portable; it measures Newton's law of cooling proportionality constant with $2 \%$ error and Stefan's law proportionality constant with $3 \%$ error and it is inexpensive.

\section{HARDWARE AND SOFTWARE DESIGN}

In this present work $12 \mathrm{~V}, 2$ watt tungsten filament bulb is used. The temperature sensor LM35, current sensing $0.44 \Omega$ shunt resistor voltage divider circuit is used for measurement of temperature, current and voltage. Here LM 35 gives $10 \mathrm{mV}$ increment for $1{ }^{\circ} \mathrm{C}$ increase in temperature. The voltage drop across $0.44 \Omega$ shunt resistor gives the current flowing through the tungsten bulb. The simple $10 \mathrm{k} \Omega$ and $5 \mathrm{k} \Omega$, voltage divider circuit gives the supply voltage for tungsten bulb. The out puts of temperature sensor, voltage drop across $0.44 \Omega$ shunt resistor and voltage from $10 \mathrm{k} \Omega$ and $5 \mathrm{k} \Omega$ voltage divider circuit are analog inputs. For the measurement of these parameters MAXIM Company ADC is used namely MAX197. The main features of the MAX197 are, +5V single supply operating voltage, $0-10 \mathrm{~V}$ analog input channels, 8 -channels provided and 12-bit ADC. The 100uF capacitor between CLK pin of the MAX197 and ground sets the frequency to $1.56 \mathrm{MHz}$. Here in between the MAX197 and voltage and current measurement a signal conditioning circuit is employed. The signal conditioning circuit is designed using OP 07 op-amp. The schematic diagram and hardware photograph is given below fig.1.a and fig.1.b.

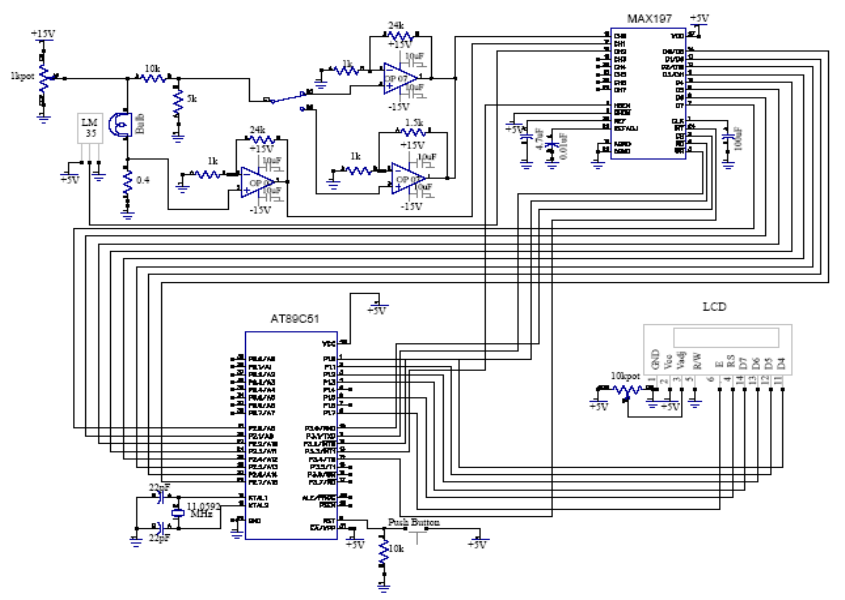

Fig. 1. a. Schematic diagram for tungsten heat loss measurement system

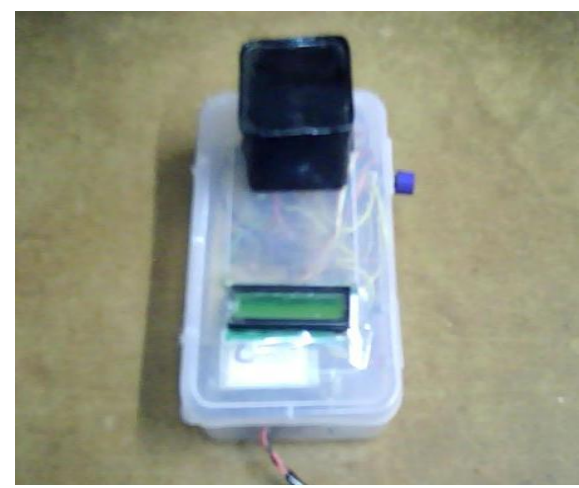

Fig. 1. b. Photograpgh of the heat loss measurement system

The voltage drop across the $0.44 \Omega$ shunt resistor is amplified to 25 times using OP 07 because that voltage is easily measurable with the MAX197.the voltage applied to the tungsten bulb is measured using two OP 07 non-inverting voltage amplifier. The non-inverting voltage amplifier with 25 gain is used for measurement of $0-200 \mathrm{mV}$. while the 
non-inverting voltage amplifier with 2.5 gain is used for measurement of $200 \mathrm{mV}-14 \mathrm{~V}$. The temperature is directly measured using LM35.

Here in this paper KEIL software is used for programming AT89C51. The output voltages of temperature sensor LM35, $0.44 \Omega$ shunt resistor and voltage divider circuit are fed to the MAX197 12-bit ADC. The corresponding digital outputs are programmed using AT89C51 and their readings are displayed on LCD.

\section{EXPERIMENTAL RESULTS}

The cold temperature of the tungsten filament is important parameter for determination of tungsten filament temperature. The empirical relation between the tungsten temperature and the cold resistance is used for measurement of temperature of the filament. The equation is given below.

$$
\mathrm{T}=300\left(\mathrm{R} / \mathrm{R}_{300}\right)^{0.82}
$$

Here $\mathrm{R}$ is the resistance of the bulb and $\mathrm{R}_{300}$ is the cold temperature of the bulb. Here Origin 7.5 graph plotting software is used for data analysis.

\section{A. Determination of Cold Resistance of Tungsten Bulb R300}

Cold resistance of the tungsten filament is determined from the slope of the graph V and I. The provided power dissipated in the filament is so small that there is no noticeable increase of temperature of the filament. Under this condition the slope of the graph gives the resistance of the filament. The below figure 2.a shows the graph of voltage applied to the bulb against the current through the bulb. The slope of the straight-line is $4.10 \Omega$ which is the resistance of the tungsten bulb.

\section{B. Determination of Newton's Cooling Proportionality Constant A}

At lower temperature of the tungsten bulb the heat loss due to the radiation is negligible. The most of the power applied to the bulb is dissipated in the form of Newton's cooling effect. The below figure 2.b shows the graph of $\mathrm{P}$ against $\left(\mathrm{T}-\mathrm{T}_{0}\right)$. The slope of the straight-line $105.55 \times 10^{-6} \mathrm{~W} / \mathrm{K}$ represents Newton's cooling proportionality constant a.

\section{Determination of Stefan'S Radiation Law Proportionality Constant $B$}

At higher temperature of the filament the heat loss is due to radiation and due to the conduction-convection is negligible. The below figure 2.c shows the graph of the $\mathrm{P}_{\mathrm{r}}\left(\mathrm{P}-\mathrm{a}\left(\mathrm{T}-\mathrm{T}_{0}\right)\right.$ against $T^{4}$. the slope of the graph is $12.44 \times 10^{-14} \mathrm{~W} / \mathrm{K}^{4}$ represents the Stefan's radiation law constant $b$.
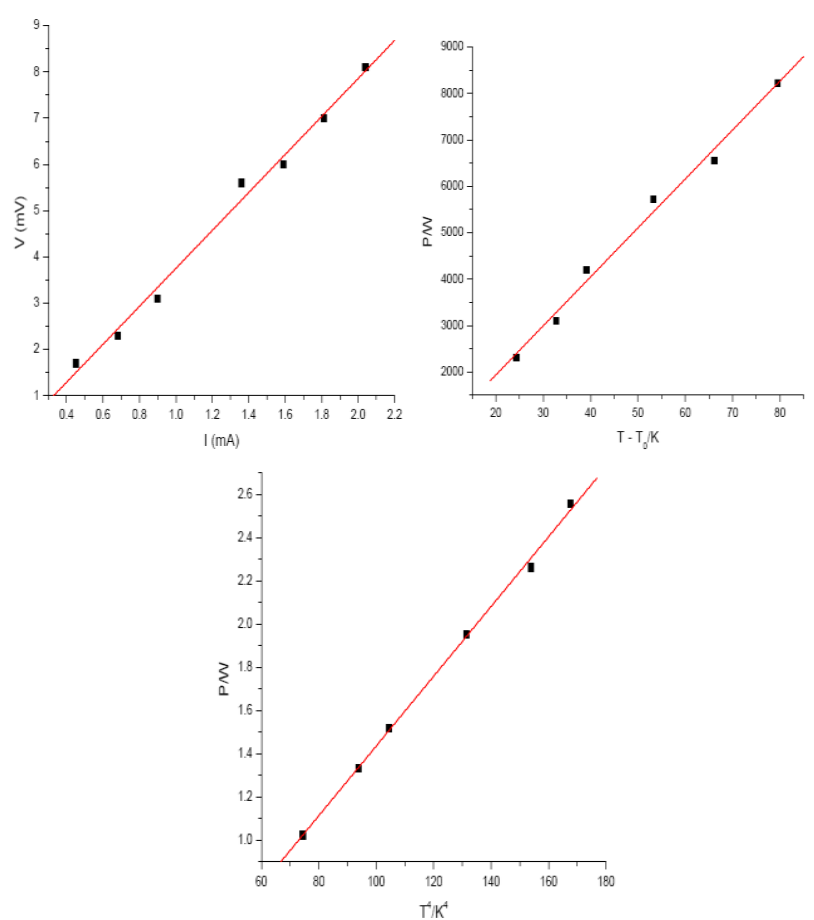

Fig. 2. (a) Graph for determing the cold resistance of the tungsten; (b) Graph for determination of a. (c) Graph for determination of $b$.

\section{CONCLUSIONS}

This paper explains the heat loss from the tungsten filament bulb. This simple experimental setup explains the heat loss from the hot bodies. In general the heat losses from the hot bodies take place in three ways i.e. conduction, convection and radiation losses. This simple experiment explains the effectively the heat loss from the tungsten bulb. Here the Newton's cooling proportionality constant (a) $105.55 \times 10^{-6} \mathrm{~W} / \mathrm{K}$ and Stefan's radiation proportionality constant (b) $12.44 \times 10^{-14} \mathrm{~W} / \mathrm{K}^{4}$ are determined.

\section{REFERENCES}

[1] I. R. Edmond, "Stefan-Boltzmann law in laboratory," American J. Physics 1968, vol. 36, no. 845 .

[2] E. M. Wray, “A Simple test of Stefan's law,” Physics Education (U. K) Jan 1975, vol. 10, no. 25.

[3] B. S. N Prasad and Rita Mascarenhas, "A Laboratory experiment on the application of Stefan's law to tungsten filament electric lamp," American J. Physics April 1978, vol. 46, no. 4, pp. 420-423.

[4] Ian cooper, "Physics with a car headlamp and a computer," Physics Education 1997, vol.32, no.3, pp. 197-200.

[5] Mark Wellons, "The Stefan-Boltzmann law," Physics department, the college of Wooster, Wooster, Ohio 44691, USA, May 9, 2007.

[6] Nazia Omar, Rozli Zulkifli, and Rosilah Hassan, "Development of a Virtual Laboratory for Radiation Heat Transfer," European Journal of Scientific Research 2009, vol.32, no.4, pp.562-571.

[7] Imtiaz Ahmad, Sidra Khalid, and Ehsan E.Khawaja, "Filament temperature of low power incandescent lamps: Stefan-Boltzmann law," Lat. Am. J. Phy. Edu. Jan 2010, vol.4, no.1, pp.74-78.

[8] Wagner and S. William, "Temperature and color of Incandescent lamp," Physics Teacher March 1991; vol.29, no.3, pp.176-177.

[9] Muhammed Ali Mazidi, Janice Gillispie Mazidi, and Rolin D.McKinlay, "The 8051 Microcontroller and Embedded Systems," using assembly and C, Second Edition. Pearson Education; India, 2006.

[10] AT89C51 datasheet, www.atmel.com.

[11] MAX197 and OP07 datasheets, www.maxim.com. 